\title{
Kendi Kendine Yardım Temelli Çevrimiçi Psikososyal Destek Platformunun Geliştirilmesi
}

\author{
Ömer ÖZER¹, Aydoğan Aykut CEYHAN²
}

\begin{abstract}
Özet
Bu çalışmanın amacı, Kendi Kendine Yardım Temelli Çevrimiçi Psikososyal Destek (KKY) platformunun pandemi sürecinde geliştirilmesine ve ön değerlendirmesinin yapılmasına yönelik çalışmaları betimlemek ve uygulamanın genel özelliklerini paylaşmaktır. KKY platformu, pandemi ile birlikte bireylerin psikolojik yardım arama ihtiyacının belirginleşmesi ve bu yönde çabalarının yoğunlaşması sonucu ortaya çıkmıştır. KKY platformu geliştirme çalışmalarında ADDIE tasarım modelinin analiz, tasarım, geliştirme, uygulama ve değerlendirme basamakları izlenmiştir. Çalışmalar sonucunda, pandemi sürecinde artış gösteren psikolojik belirtilerle başa çıkma konusunda kullanıcılara destek olmayı amaçlayan, bilişsel davranışçı terapi yaklaşımına dayalı olarak geliştirilmiş, internet tabanlı bir kendi kendine yardım uygulaması ortaya çıkmıştır. Platform içerisinde depresif duygudurum, kaygı ve stres konularını içeren üç modül ve bir gevşeme egzersizi alanı mevcuttur. Modüllerin her biri aşamalı biçimde oluşturulmuş beş oturum içeriğinden oluşmaktadır. Modüllerin içeriğinde ise bilgilendirici metinler, psikoeğitim amaçlı animasyonlar, belirti düzeyini değerlendiren soru listeleri, kullanıcının kendi kendine doldurabileceği formlar ve bilgi düzeyini değerlendiren mini testler yer almaktadır. Platformu kullanmak isteyen bireyler, https://kendikendineyardim.anadolu.edu.tr ve http://www.kendikendineyardim.org adresinden platforma erișim sağlamakta ve öncelikle kullanıcı kaydı olușturmaktadırlar. Sonrasında psikolojik belirti düzeylerini ölçen ölçme aracını tamamlayarak modül içeriklerinde çalışmaya başlamaktadırlar. Uzman desteksiz bir kendi kendine yardım müdahalesi olan KKY Platformu psikolojik belirtilerle başa çıkmada kullanıcılara destek olacak bir uygulamadır.
\end{abstract}

Anahtar kelimeler: Kendi Kendine Yardım, Web Temelli Müdahale, Pandemi, Psikolojik Belirtiler

\footnotetext{
1 Öğr. Gör. Dr., Psikolojik Danışma ve Rehberlik Merkezi, Anadolu Üniversitesi, Eskişehir

İlgili yazar e-posta/ Corresponding author e-mail: omer ozer@anadolu.edu.tr ORCID No: 0000-0003-2740-2723

2 Prof.Dr., Eğitim Fakültesi, Rehberlik ve Psikolojik Danışmanlık ABD, Anadolu Üniversitesi, Eskişehir

e-posta/e-mail: aceyhan@anadolu.edu.tr ORCID No: 0000-0003-0174-3642

*Bu çalış̧ma Bursa Eskişehir Bilecik Kalkınma Ajansı tarafindan desteklenmiştir (Proje No: TR41/20/COVID/0022).
}

Bu makaleye atıf yapmak için- To cite this article Özer, Ö. ve Ceyhan, A. A. (2021). Kendi Kendine Yardım Temelli Çevrimiçi Psikososyal Destek Platformunun Geliștirilmesi. Afet ve Risk Dergisi, 4(2), 371-386. 


\title{
Development of Self-Help Based Online Psychosocial Support Platform
}

\begin{abstract}
The aim of this study is to describe the studies on the development and pre-evaluation of the Self-Help Based Online Psychosocial Support (KKY) platform during the pandemic process and to share the general features of the application. The KKY platform has emerged as a result of the pandemic, the need for individuals to seek psychological help and the intensification of their efforts in this direction. Analysis, design, development, implementation and evaluation steps of the ADDIE design model were followed in the KKY platform development studies. As a result of the studies, an internet-based self-help application developed based on the cognitive behavioral therapy approach, which aims to support users in coping with the increasing psychological symptoms during the pandemic process, has emerged. There are three modules on depressive mood, anxiety and stress and a relaxation exercise module within the platform. Each of the modules consists of five session contents that are created in stages. In the content of the modules, there are informative texts, animations for psychoeducational purposes, question lists that evaluate the symptom level, forms that the user can fill in himself, and mini-tests that evaluate the level of knowledge. Individuals who want to use the platform access the platform at https://kendineyardim.anadolu.edu.tr and first create a user registration. Afterwards, they complete the measurement tool that measures psychological symptom levels and start working on the module contents. KKY Platform, which is a self-help intervention without expert support, is an application that will support users in coping with psychological symptoms.
\end{abstract}

Keywords: Self Help, Web Based Interventions, Pandemi, Psychological Syptomps

\section{GİRİş}

Gelişen teknoloji ve buna paralel olarak yaygınlaşan internet kullanımı insan yaşamında önemli değişimler ortaya çıkarmıştır. Bu değişimi yaşamının tüm yönlerinde görmek olasıdır. Bu kapsamda insanların psikolojik yardım arama ve alma davranışlarında da internet teknolojisinin getirdiği değişimler ve çeşitlilik söz konusudur. Nitekim, psikolojik yardım hizmetlerinde son yıllarda e-posta ya da anlık mesajlaşma uygulamaları ile yürütülen terapi ve danışmanlık hizmetleri, senkronize görüntü ve ses içeren çevrimiçi psikolojik danışma oturumları, özellikle maruz bırakma alanında kullanılan sanal gerçeklik terapileri ve internet tabanlı müdahaleler önemli bir yer tutmaya başlamıştır. Ayrıca, psikolojik yardım hizmetlerinde sıklıkla kendi kendine yardım uygulamalarına da yer verilebilmekte ve bu amaçla internet teknolojisinden de etkin biçimde yararlanılabilmektedir.

Psikolojik yardım hizmetlerinde kendi kendine yardım müdahaleleri, Rosen'in (1987) kendi kendine yardım kitaplarına eleștirel bir bakış açısı ile yaklaştığı ve kendi kendine yardım kitaplarını psikoterapinin ticarileştirilmesi olarak betimlediği çalışmasından beri hem klinik uygulamada hem de araştırma bağlamında giderek önem kazanan bir konu haline gelmiştir. Gelişen teknoloji ile birlikte kendi kendine yardım uygulamaları bilgisayar ve internet destekli uygulamaları da içerecek biçimde geniş bir çalışma alanı haline dönüşmüştür. Günümüzde, internet vasıtası ile sağlanan kendi kendine yardım programları, çevrimiçi tabanlı- web based(Johansson vd., 2017) veya internet aracıllğı ile sağlanan -internet delivered- (Kazlauskas, Eimontas, Olff, Zelviene ve Andersson, 2020) sistemler şeklinde farklı isimlendirmelere de sahiptir. Farklı biçimlerde isimlendirilmekle birlikte bu programlar temelde bir web sitesi aracılığıyla işletilen ve sağlık ve ruh sağlığı ile ilgili yardım arayan bireyler tarafından kullanılan, çevrimiçi bir program aracllı̆̆ıyla işleyen ve kullanıcının kendi kendine yönlendirdiği yapılandırılmış müdahale programını ifade etmektedir (Barak, Klein ve Proudfoot, 2009). Bu kapsamda da üç farklı biçimde internet temelli müdahale söz konusu olabilmektedir. Bunlardan ilki sadece bilgi veren eğitim içeriklerine programda yer verilmesidir. Bir diğeri ise bireylere kendi kendine yardım sürecinde kullanabilecekleri terapötik müdahaleler sunulmasıdır. Son 
olarak ise uzmanın düzenli olarak kullanıcıya bilgi verdiği uzman destekli müdahalelere programda yer verilmesidir. Ayrıca, gerekli durumlarda e posta, sistem üzerinden geribildirim sunma, yüz yüze veya çevrimiçi senkron biçiminde psikolojik danışma oturumları gerçekleștirilmek sureti ile de kendi kendine yardım uygulamaları desteklenebilmektedir. $\mathrm{Bu}$ müdahale türlerine ek olarak son dönemde kullanıcıların ihtiyaçlarına göre karar alabilen otonom müdahaleler içeren yapay zeka destekli yazılımlara da programlarda yer verilebildiği görülmektedir (Barak vd., 2009). Söz edilen tüm bu çevrimiçi tabanlı kendi kendine yardım uygulamaları/müdahaleler ise internet siteleri ya da akıllı telefonlar vasıtası ile etkisi bilimsel olarak kanıtlanmış yöntemleri kullanıcılara uygun maliyetler (çoğu zaman ücretsiz ) ile erişim olanağı sunmaktadır (Yuen vd., 2016). Ayrıca, çevrimiçi müdahalenin yer aldığı uygulamaların kullanıcısı olan danışanlar, problemleri ile başa çıkmak ve yardım sağlamak için psikolojik yardım tekniklerini kendine uygulayabilmekte ve problemleri ile başa çıkma becerilerini geliştirebilmekte ve özgürce istedikleri zaman ve mekanda bu yardımı alabilmektedirler. Nitekim alanyazında, bu tür müdahalelerin program geliştirildikten sonra sınırsız kullanıcıya erișebilmesi nedeniyle ekonomiklik, etkisi kanıtlanmış yöntemleri herkesin erişimine sunması nedeniyle standardizasyon sağlayacağı ifade edilmektedir. Bunun yanında kendi kendine yardım sistemleri internet bağlantısı olan herkes tarafından ulaşılabilir olması sayesinde erişilebilirlik ve sistemin güvenli olması ve anonim kimliklerle kullanılabilmeye olanak sağlaması ve böylece bireylerin kendilerini daha rahat hissedebilmesi sayesinde gizlilik gibi çok sayıda avantaja da sahip olduğu ifade edilmektedir (Khanna, Aschenbrand ve Kendall, 2007).

Günümüzde, çevrimiçi temelli kendi kendine yardım müdahale programları oldukça popüler uygulamalar haline gelmiştir. Özellikle, toplumsal olarak psikolojik belirtilerin ve problemlerin giderek arttığı dönemlerde mevcut uzman sayısının başvuruları karşılamakta yetersiz kaldığı ve herkesin uzman ruh sağlığı çalışanlarına ulaşma olanağının bulunmadığı durumlarda bir tür önleyici müdahale biçimi olarak çevrimiçi temelli kendi kendine yardım uygulamalarının önemli bir gereksinimi karşılaması söz konusudur. Ayrıca, yaşadığımız bu pandemi sürecinde dünya genelinde pek çok bireyin bu zorlu süreç ile başa çıkmada zorlanabilmesi ve ruh sağlığında önemli bozulmalar ile karşılaşması olasıdır. Bunu destekler biçimde, araştırma bulguları da COVID 19 salgının başladığı ülke olan Çin Halk Cumhuriyeti'nde salgının başlangıç döneminde genel popülasyonda depresif duygudurum, anksiyete ve stres düzeylerini inceleyen bir tarama çalışması katılımcıların \%53.8'inin salgının psikolojik etkilerine sahip olduğunu,\%16.5'inin ortaüst depresif duygudurum, \%28.8'i yoğun anksiyete belirtileri, \%8.1'inin yüksek stres belirtisi yaşadığını ortaya koymaktadır (Wang vd., 2020). Bu süreçte pek çok bireyin psikolojik yardım ihtiyaçlarının da önemli ölçüde arttığı ve bu yardımın da çoğunlukla çevrimiçi psikolojik yardım uygulamaları ile gerçekleștirildiği ve bu durumunda toplum ruh sağlığı açısından önemli olduğu vurgulanmaktadır (Gaebel ve Stricker, 2020; Riva vd., 2020; Yang, Yin, Wang, Rahman ve Li, 2020). Dolayısıyla, bu zorlu süreçte, bireylere çevrimiçi temelli kendi kendine yardım uygulamaları yoluyla da hizmetlerin verilmesi, ruh sağlığına yönelik önleyici, koruyucu ve iyileştirici işlevlerin yerine getirilmesine de önemli katkılar sağlayabilmektedir. Buna ilişkin alanyazında çevrimiçi temelli kendi kendine yardım uygulamalarının etkililiğine yönelik önemli bir bilgi birikimi de mevcuttur.

Alanyazında internet temelli kendi kendine yardım uygulamaları konusundaki araştırma bulguları, çocuk, ergen ve yetişkin örneklemlerde, klinik tanı almış ya da klinik tanı almamış gruplarda müdahalelerin etkililiğini ele almaktadır. Bu bağlamda depresif duygudurum (Buntrock vd., 2016; Lambert vd., 2018; Van Straten, Cuijpers ve Smits, 2008), sosyal anksiyete (Boettcher vd., 2018; Stolz vd., 2018), obsesif kompulsif bozukluk (Lee, Hoepfl, Werner ve McIngvale, 2019), patolojik kumar (Baumgartner vd., 2019; Wittekind vd., 2019), alkol bağımlılığı (Radtke, Ostergaard, Cooke ve Scholz, 2017; M. P. Schaub vd., 2018; M. Schaub, Sullivan, Haug ve Stark, 2012), stres yönetimi (Meredith ve Frazier, 2019; Urech vd., 2018), intihar düşüncelerini azaltma (De Jaegere vd., 2019; Torok vd., 2020; van Spijker vd., 2015) gibi bir çok alanda internet temelli kendi kendine yardım uygulamaları geliştirilmiştir. $\mathrm{Bu}$ alanda gerçekleştirilen metanaliz çalışmaları da, internet tabanlı kendi kendine yardım müdahalelerin etkililiğine işaret etmektedir 
(Barak, Hen, Boniel-Nissim ve Shapira, 2008; Buscher, Torok ve Sander, 2019; Cowpertwait, Clarke, Cowpertwait ve Clarke, 2013; Hartmann-Boyce, Jebb, Fletcher ve Aveyard, 2015; Riper vd., 2011; Sevilla-Llewellyn-Jones, Santesteban-Echarri, Pryor, McGorry ve Alvarez-Jimenez, 2018; Wantland, Portillo, Holzemer, Slaughter ve McGhee, 2004). Bu bulgularda, çevrimiçi kendi kendine yardım uygulamalarının psikolojik yardım ve psikolojik danışmanlık açısından önemli bir işleve sahip olduğunu göstermektedir. Dünya genelinde çok sayıda ve çeşitlilikte çevrimiçi kendi kendine yardım uygulamaları mevcuttur ve bu uygulamalar etkin bir biçimde kullanılmaktadır. Bununla birlikte, Türkiye'de çevrimiçi psikolojik yardım hizmetleri, özellikle internet temelli kendi kendine yardım uygulamaları günümüze kadar söz edilmekle birlikte etkin ve yaygın bir biçimde kullanılan bir yardım ve müdahale biçimi değildir. Türkiye'de internet ve psikolojik yardım konusunu birlikte ele alan çalışmalar çoğunlukla çevrimiçi psikolojik danışma hizmetlerinin tanıtımına ve uygulamasına yönelik açıklayıcı kuramsal bakış açısı, bu alana yönelik etik değerlendirmeler, algılar ve küçük örneklemlerde yapılan uygulamaların nitel değerlendirmesi ile sınırlıdır (Durdu Akgün, Aktaç ve Yorulmaz, 2019; Erdem ve Özdemir, 2020; Koçyiğit ve Erkan, 2021; Özdemir ve Barut, 2020; Özer, Yıkılmaz, Altınok ve Bayoğlu, 2016; Zeren, 2014; Zeren ve Bulut, 2018).

Son yıllarda yaşanılan pandemi süreci, Türkiye'de çevrimiçi psikolojik yardım hizmetlerine ve uygulamalarına duyulan gereksinimin daha fazla hissedilmesine ve araştırmacıların bu yönde çabaların yoğunlaşmasına da yol açmıştır. Ayrıca pandemi süreci ile birlikte Türkiye'de pandemi kaynaklı ekonomik, sosyal, psikolojik zorlanmaların söz konusu olabileceğinden hareketle pek çok kurum bu alandaki çalışmaları desteklemiştir. Bu kapsamda TÜBİTAK, Sanayi ve Teknoloji Bakanlığı, Sağlık Bakanlığı gibi kuruluşlar proje destek çağrıları yayınlamıștır. Bu durum bir taraftan, acil durumlarda etkili bir biçimde kullanılabilecek, aynı zamanda daha geniş kitlelere ulaşabilecek müdahale araçlarına olan ihtiyacı da yansıtmaktadır. Bu çalışmada bu ihtiyaca yanıt verebileceği düşünülen Kendi Kendine Yardım Temelli Çevrimiçi Psikososyal (KKY) Destek Platformu (http://kendikendineyardim.org) isimli web uygulamasının geliştirilmesine ve ön değerlendirmesinin yapılmasına yönelik çalışmaları betimlemeyi ve uygulamanın genel özelliklerini paylaşmayı amaçlamaktadır.

\section{KKY PLATFORMU GELİSTIRME SÜRECI}

Çevrimiçi psikolojik yardım veren kendi kendine yardım sistemleri temelde kullanıcılara etkisi kanıtlanmış psikolojik danışma müdahalelerinin içeriğini ve uygulamasını öğretmeyi hedefleyen platformlardır. Bunun içinde Kendi Kendine Yardım Temelli Çevrimiçi Psikososyal (KKY) Destek Platformu'nun geliştirilmesine yönelik çalışmalar, uzaktan öğretim tasarımına dayalı olarak gerçekleştirilmiştir. Bu kapsamda platform geliştirilirken uzaktan öğretim tasarım modeli olan ADDIE (Analysis, Design, Development, Implementation, Evaluation) öğretim tasarımı modeli basamakları dikkate alınmıştır. ADDIE modelinde süreç basamaklar halinde işletilir ve her bir basamağın çıktısı diğer basamağın girdisini oluşturur (Özerbaş ve Kaya, 2017). ADDIE modeli, hem çevrimiçi hem de yüz yüze ortamlardaki öğretim tasarımları için kullanışlı bir model olarak değerlendirilmektedir (Aldoobie, 2015). Bu modelde sırasıyla analiz, tasarım, geliştirme, uygulama ve değerlendirme basamakları işletilir. Analiz basamağında hedef kitlenin ihtiyaçları değerlendirilir. Tasarım basamağında ölçme araçlarının belirlenmesi, içeriğin hazırlanması ve öğretim hedeflerinin belirlenmesi söz konusudur. Geliştirme basamağında modüllerin içerikleri hazırlanır ve bunlar çevrimiçi ortama aktarılır. Uygulama basamağı pilot uygulamayı içerir ve kullanıcıların sistemde yer aldığı basamaktır. Son basamak olan değerlendirme basamağında ise sistemin ara değerlendirmesi yapılarak gerekli düzenlemeler gerçekleştirilir.

Kendine Yardım Temelli Çevrimiçi Psikolojik (KKY) Destek Platformunun geliştirme sürecinde ADDIE modelinin basamakları izlenmiştir. Bu çerçevede KKY'nin geliştirilme sürecinde izlenen 
analiz, tasarım, geliştirme, uygulama ve değerlendirme basamakları sırasıyla aşağıda açıklanmaktadır.

\subsection{Analiz}

KKY platformunun hedefleri ve kapsamı belirlenirken ilk aşamada kapsamlı bir literatür değerlendirilmesi gerçekleştirilmiştir. Özellikle salgın dönemleri ve sonrasındaki psikoloji araştırmaları incelenmiştir. Bu çerçevede, alanyazında SARS salgınının uzun dönemli etkilerini ve salgının psikolojik etkilerini değerlendiren çalışmalarda da salgında sıklıkla kaygı, korku, depresif belirtiler gibi belirtilerin artış gösterdiğinin (Cava, Fay, Beanlands, McCay ve Wignall, 2005; Pan, Chang ve Yu, 2005) ifade edildiği görülmüştür. Türk Psikiyatri Derneği (2020) Ruhsal Travma ve Afet Çalışma Birimi tarafından yayınlanan bilgilendirme dosyasında, karantina süreci ve alınan tedbirlerin ruhsal zorluklara yol açacağı vurgulanmış, kafa karışıklığı, konsantrasyon bozukluğu, korku, öfke, suçluluk hissi, matem hisleri, uyuşukluk, tükenmiş hissetme ve kaygıya bağlı uykusuzluğun en yaygın psikolojik yakınma olduğu, en yaygın psikiyatrik problemlerin ise akut stres bozukluğu, travma sonrası stres bozukluğu, majör depresyon, yaygın anksiyete bozukluğu ve uyum bozukluğu olduğunu ifade edilmiștir. Bu bilgiler kapsamında, KKY platformunun geliştirme sürecinde yer alan araștırmacılar destek aldıkları proje süresinin sınırlılığını ve pandemi sürecinde bireylerin giderek artan ihtiyaçlarını dikkate alarak öncelikle üç alanda (depresif duygudurum, kaygı ve stres) platform içeriğinin hazırlanmasını kararlaştırmışlardır. Böylece, KKY platformu içeriği depresif duygudurum, kaygı ve stres modülleri içermiştir. Bu içeriklerin pandemi sürecinde pek çok birey tarafından psikolojik yardım için öncelikle ihtiyaç duyulan içerikler olduğu, pandemi sürecinde gerçekleştirilen benzer alanyazın çalışmalarında da belirtilmektedir. Nitekim, COVID 19 salgınının ilk dönemlerinde Çin'de yapılan bir tarama çalışmasında depresyon, anksiyete, somatizasyon ve fobik anksiyete alt boyutlarında daha önce yapılan norm çalışmasına göre anlamlı bir artış olduğu vurgulanmaktadır (Tian vd., 2020). Salgın sonrası süreçteki çalışmaları değerlendiren bir meta analiz çalışmasında travmatik stres, anksiyete, obsesif kompulsif belirtiler ve depresif duygudurum belirtileri pandeminin psikolojik etkileri olarak ifade edilmektedir (Brooks vd., 2020).

\subsection{Tasarım}

Tasarım aşaması, ADDIE modelinde öğrenme hedeflerinin belirlendiği aşamayı içermektedir. $\mathrm{Bu}$ kapsamda proje ekibi ve içerik geliştiriciler platform içeriğini belirlemişlerdir. İnternet temelli kendi kendine yardım içeriklerinin geliştirilmesinde farklı psikolojik yardım yaklaşımları kullanılabilmektedir. Bu kapsamda psikanalitik yaklaşım ile geliștirilen bir uygulamanınhastaların depresyon, anksiyete ve yaşam doyumları üzerinde etkili olduğu ifade edilmiştir (Zwerenz vd., 2017). Tek bir kuramsal temele dayanan platformlar olduğu gibi bazı çalışmalarda bilişsel davranışçı terapi tekniklerinin yanı sıra, pozitif psikolojiye ait etkinlikler de aynı platform içerisinde kullanılmıştır (Roepke vd., 2015). Ancak alanyazında uygulamaların ağırlıklı olarak bilişsel davranışçı terapi yöntemi ile yapılandırıldığı, farklı ekollere dayanan müdahalelerin sınırlı olduğu vurgulanmaktadır (Andersson vd., 2008). Bu kapsamda bu çalışmada da, pandemi sürecinde öncelikle KKY platformunun bilişsel davranışçı terapi yaklaşımı bağlamında geliştirilmesinin, bu süreçte bireylere etkin psikolojik yardım ve destek açısından daha işlevsel olacağı öngörülmüştür. Bunun için platformun içeriğinin tasarımında bireylere probleme ilişkin psikoeğitim sunulması, ișlevsel olmayan düşüncelerin belirlenmesi, bu düşüncelerin ele alınması, davranış müdahaleleri planlama ve uygulama becerilerinin kazandırılması, kullanıcıların problem alanına yönelik bilişsel terminolojiyi öğrenebilmesi (otomatik düşünce, bilişsel çarpıtmalar gibi) öğrenme hedefleri olarak belirlenmiștir. Bu hedefler bağlamında modül içerikleri oluşturulmuştur.

\subsection{Geliştirme}

Geliştirme basamağı hem içeriğin geliştirilmesi hem de internet tabanlı platformun geliştirilmesini içermektedir. Uygulamanın içerik geliştirme sürecinde proje ekibinde yer alan araştırmacılar, içerik geliştiriciler ve danışman koordineli biçimde çalışmışlardır. Proje ekibi 
psikolojik danışma rehberlik alanında doktorasını tamamlamış iki araștırmacı ve psikolojik danışma ve rehberlik alanında profesör unvanına sahip iki akademisyenden oluşmuştur. İçerik geliştirme sürecinde psikolojik danışma alanında görev yapan dört uzman, psikoloji alanında görev yapan iki uzman ve psikiyatri alanında görev yapan bir uzman görev almışlardır. Geliştirme sürecinde yer alan tüm araştırmacılar ve içerik geliştiriciler bilişsel davranışçı terapi alanında teorik ve uygulamalı eğitim programlarını tamamlamış deneyimli aktif olarak ruh sağlı̆̆ı alanında çalışmaktadırlar ve bilişsel davranışçı psikoterapiler alanında akademik yayınlara sahiptirler.

Geliştirme basamağında KKY platformunda yer alan her bir modül için bir çalışma grubu oluşturulmuştur. Çalışma grupları her bir modül için beş oturumdan oluşan içerikleri hazırlamıștır. İçeriğin hazırlanması sürecinde kendi kendine yardım kitapları ile bilișsel davranışçı terapi temelli psikoeğitim programlarının içerikleri incelenmiştir. Depresyon, anksiyete ve stresi açıklayan bilişsel modeller incelenmiştir (Hamilton ve Dobson, 2002; Hofmann, 2007, Clark ve Steer, 1996). İçerik etkinlikleri belirlenirken etkisi bilimsel olarak kanıtlanmış ve sıklıkla kullanılan müdahale yöntemleri seçilmiştir. Hazırlanan içerikler proje ekibindeki araştırmacılar tarafından gözden geçirilmiştir. Son olarak içerikler, bilişsel davranışçı terapi alanında yetkin psikiyatri uzmanının danışmanlığında gözden geçirilerek gerekli düzenlemeler yapılmıștır. Modüllerin isimleri ve kısa içerikleri Tablo 1'de gösterilmektedir.

Tablo 1. Modül İçerikleri

\begin{tabular}{|c|c|c|c|}
\hline Modül Adı & $\begin{array}{l}\text { Depresif } \\
\text { Duygudurum }\end{array}$ & $\begin{array}{l}\text { Kaygı Problemleri } \\
\text { ile Başa Çıkma }\end{array}$ & $\begin{array}{l}\text { Stres } \\
\text { ile Bașa Çıkma }\end{array}$ \\
\hline Oturum 1 & $\begin{array}{l}\text { Depresif } \\
\text { duygudurum nedir? }\end{array}$ & Kaygı nedir? & Stres nedir? \\
\hline Oturum 2 & $\begin{array}{l}\text { Davranışsal } \\
\text { aktivasyon }\end{array}$ & Düşünce dünyamız & Progresif kas gevşetme \\
\hline Oturum 3 & Düşünce dünyamız & Otomatik düşüncelere karşı çıkmak & $\begin{array}{l}\text { Duygu düşünce } \\
\text { davranış iliş̧isisi }\end{array}$ \\
\hline Oturum 4 & $\begin{array}{l}\text { Düşüncelerle } \\
\text { çalışmak }\end{array}$ & Davranış deneyi & Stres saati \\
\hline Oturum 5 & $\begin{array}{l}\text { Tekrarlayan } \\
\text { düşüncelerle başa } \\
\text { çıkmak }\end{array}$ & Kaygılarla yüzleşmek & Sorun çözme \\
\hline
\end{tabular}

Tablo 1'de de görüleceği üzere, uygulama depresif duygudurum, kaygı problemleri ile başa çıkma ve stres ile başa çıkma olmak üzere üç modülden oluşmaktadır. Bu modüller ise aşamalı biçimde ulaşılabilen beşer oturum içerikten oluşmaktadırlar. Ayrıca, içerik geliştirme basamağında, KKY platformunda platform kullanıcılarının istatistiklerini takip etmek ve platformun ile bireylerin kendi gelişimlerini değerlendirmelerine katkı sağlamak üzere ölçme araçlarına da yer verilmiştir. $\mathrm{Bu}$ kapsamda kullanıcıların platforma kayıt olması sırasında bir bilgi formunu doldurmaları istenmiştir. Bu form ile kullanıcıların yaș , cinsiyet, e posta, daha önce psikolojik yardım alıp almama, COVID tanısı alıp almama, COVID kaynaklı olarak bir yakınını kayıp edip etmediği, medeni durumu, eğitim düzeyi ve aylık gelir düzeyi bilgileri elde edilmektedir. Ayrıca, platformun girişinde başlangıçta bireylerin/kullanıcıların psikolojik belirti düzeylerini belirlemeye yönelik olarak Kısa Semptom Envanteri uygulanmaktadır (Hisli Şahin ve Durak, 1994; Hisli Şahin, Durak Batıgün ve Uğurtaş, 2002). Envanter bireylerin psikolojik belirtilerini değerlendirmekte, depresif duygudurum, anksiyete, hostilite, olumsuz benlik ve somatizasyon alt boyutlarında değerlendirme yapmaktadır. Sisteme kayıt sırasında ölçme aracı doldurulmaktadır. Kullanıcı modülü tamamladığında aynı ölçme aracı son test olarak uygulanmaktadır.

Platformda, proje ekibi ve içerik geliştiricilerin müdahale programı içerikleri profesyonel seslendirme sanatçıları tarafından profesyonel stüdyo ortamında seslendirilmiştir. İçerikler, bir 
kadın ve bir erkek seslendirmen tarafından seslendirilmiştir. Ses kayıtları kullanılarak içerik ile örtüşen animasyonlar hazırlanmıştır. Animasyonlar için VYOND (https://www.vyond.com/) isimli yazılım kullanılmıștır. Aynı zamanda platformun web sayfasının hazırlanması ve platformun arka plandaki çalışan yazılım için bilgisayar/yazılım mühendislerinden hizmet alınmıştır. Proje araştırmacılarının yönlendirmesi çerçevesinde platform için gerekli yazılım hazırlanmıştır. Platformun web ara yüzü masaüstü, mobil, tablet gibi cihazlarda kullanılabilmesi için responsive tasarım özelliği ile öne çıkan Bootstrap CSS çatısı ile kodlanmıștır. Arka plan yazılımında ise PHP yazılım dili ve MySQL veritabanı kullanılmıştır. Platformun geliştirmeye açık ve güncel olması için ise geliştirmede Laravel PHP çatısı kullanılmıştır. Mevcut platform, halen 2 GB RAM, 2 CPU, 60 GB SSD Disk bulunan bir sunucuda çalışır durumdadır.

\subsection{Uygulama}

Geliştirilen platformun temel amacl, depresif duygudurum, anksiyete ve stres ile başa çıkma konusunda kullanıcılara etkisi bilimsel olarak kanıtlanmış etkinliklerin ve tekniklerin kullanımının öğretilmesi ve böylece bu deneyimler ile bireylerin psikolojik belirtileri kendi kendine yardım yolu ile azaltmalarının sağlanmasıdır. Ayrıca sistem içerisinde modüllerden bağımsız bir gevșeme egzersizi modülü bulunmaktadır. $\mathrm{Bu}$ bölüm diğer bölümler gibi oturumlardan oluşmamakta, dört farklı gevşeme egzersizi içermektedir. ADDIE Modelinin uygulama basamağında hazırlanan içerikler çevrimiçi ortama aktarılmış ve bu aktarım sürecinde tüm proje ekibi tarafından içerik ve yazılım kontrolü sağlanmıştır. Sonrasında kullanıma hazır hale gelen sistem, psikolojik danışma ve rehberlik alanında lisans mezunu olan 30 kullanıcının denemesine açılmıştır. Deneme kullanımı sonucunda platform son halini almıștır. Platformun kullanılması için bilgisayar, tablet ya da akıllı telefon ve aktif bir internet bağlantısı gerekmektedir. Kullanıclar site ana sayfasına www.kendikendineyardim.org ya da http://kendikendineyardim.anadolu.edu.tr adresinden erişebilmektedirler. Halen bu adreste kullanımda olan platformun temel kullanım özellikleri bazı örnek ekran görüntüleri eşliğinde kısaca aşağıda açıklanmaktadır.

KKY platformu web sayfasına ilk giriște kullanıcıları platformun ana sayfasıkarşılamaktadır. Ana sayfada geliştirici modüller hakkında bilgi, geliştirici ekip ve kendi kendine yardım müdahalesinin genel çerçevesi hakkında bilgiler yer almaktadır. KKY platformunun web sayfasının giriş kısmının ekran görüntüsü aşağıda Şekil 1'deki gibidir.

Şekil 1'de görüldügü üzere, web ana sayfasının içeriklerine ulaşmak için, ilk kez kullanacak bireylerin giriş kaydı yaptırması gerekmektedir. Sağdaki kayıt ol kısmından kullanıcı kaydı yapılabilmektedir. Üye kayıt olma sürecinde kullanıcılar ilk olarak bilgilendirilmiş onam formunu onaylamakta ve sonrasında üye kayıt formunu doldurmaktadırlar. Üye kayıt formunun ekran alıntısı Şekil 2'deki gibidir.

Şekil 2'den görüleceği üzere üye kayıt formunda kullanıcılar e posta, şifre, yaş, şehir, medeni durum ve daha önce psikolojik yardım alma durumu ile ilgili soruları yanıtlamaktadır. Üye kayıt formu tamamlandıktan sonra kullanıcılar psikolojik belirtileri hakkında bilgi elde etmek üzere Kısa Semptom Envanteri'ni (Hisli Şahin ve Durak, 1994) tamamlamaları gerekmektedir. Bu işlemler sonrasında kullanıcıların sisteme kayıtları gerçekleşmiş olmaktadır. Sonraki kullanımlarda ise kullanıcılar eposta ve şifrelerini kullanarak giriş kısmından modül içeriklerine erişim sağlamaktadırlar.

Giriş yapan kullanıcıları KKY Platformunun depresyon, kaygı, stres müdahale modülleri ile gevşeme egzersizi yönelik modül karşılamaktadır. Tüm modüller birbirinden bağımsız olarak yapılandırılmıştır. Her bir modül beş oturumdan oluşmaktadır ve her bir oturum tamamlanması yaklaşık 15-35 dakika arasında sürmektedir. Modülerde yer alan oturumlar aşamalı bir biçimde oluşturulmuş olup, biri tamamlanmadan diğerine geçiş söz konusu olmamaktadır. Böylece giriş yapan kullanıcı herhangi bir modülü seçerek modülün sayfasından ilk oturumuna başlamakta 
bunu tamamladıktan sonra da diğer oturumlara erişim sağlayabilmektedir. Bir modül ana sayfası örneği olarak kaygı modülünün başlangıç sayfası Şekil 3 'deki gibidir.

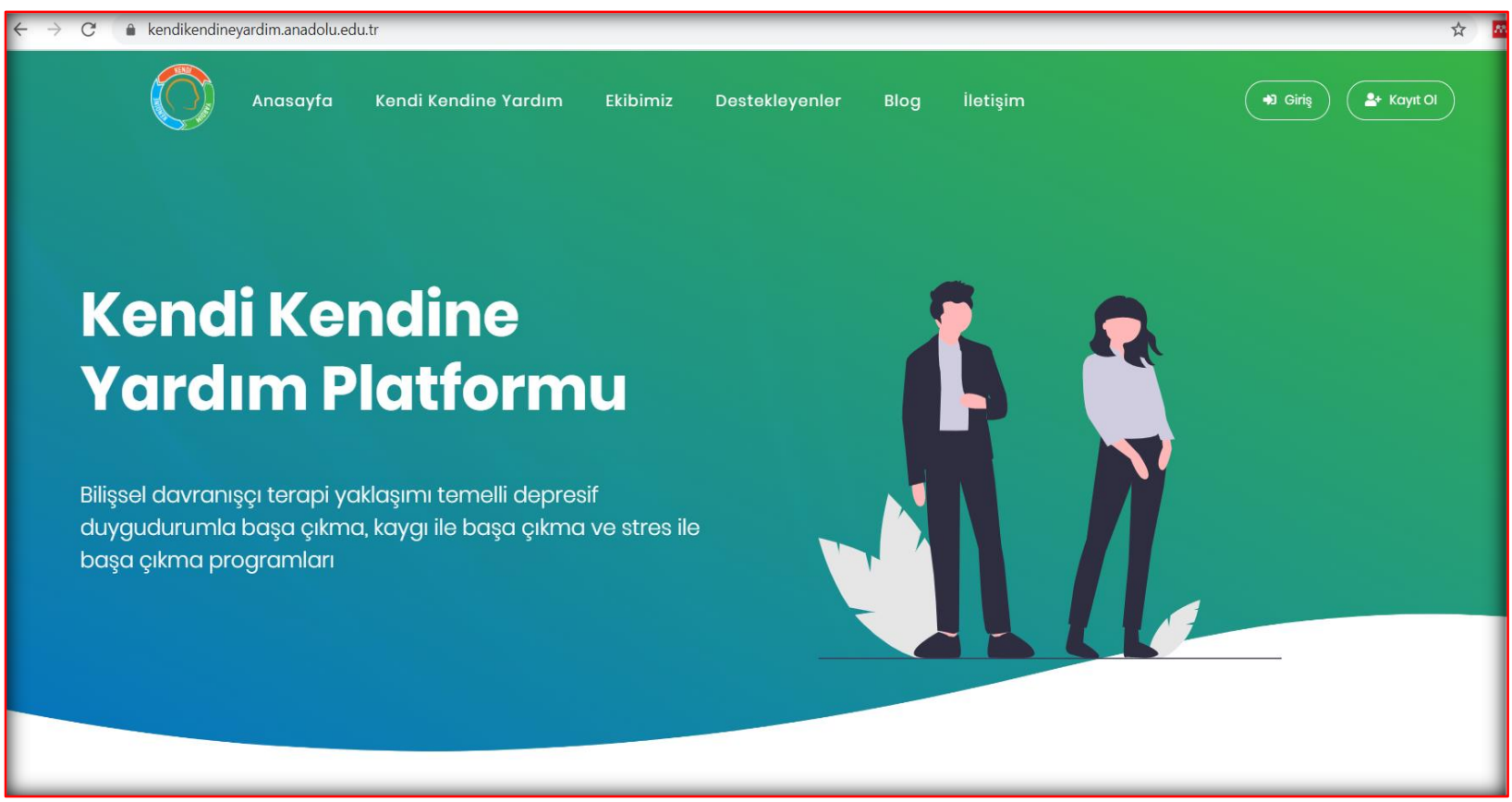

Şekil 1. Site Anasayfası

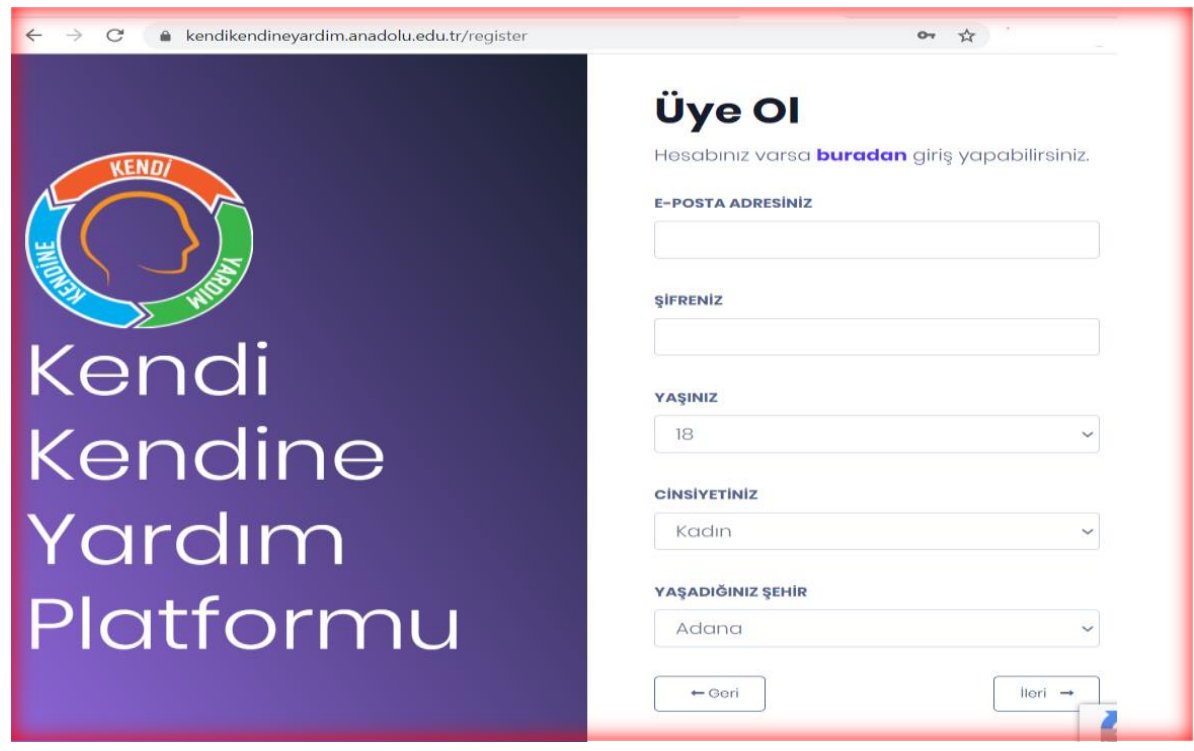

Şekil 2. Üye Kayıt Ekranı

Şekil 3'te görüleceği üzere, kullanıcılar modül ana sayfasında programın ne kadarını tamamladığını görebilmektedirler. Kullanıcılar Durumum sekmesi ile doldurduğu formlar ve ölçme araçlarına ulaşabilmekte, Uzmana sor butonu ile proje ekibine mesaj gönderebilmektedir. Kaynaklar bölümünde ise hazırlanan içeriğin indirilebilir dosya (pdf formatı) haline erişebilmektedir. Modüllerin içerisinde psikolojik belirtileri ölçen farklı soru listeleri kullanılmıştır. Aynı zamanda öğretilen içeriğin öğrenme düzeyini belirleyecek mini testler yer almaktadır. Sistem içerisinde bilişsel davranışçı terapi sürecinde kullanılan formlar (düşünce 
kayıt formu, davranış aktivasyonu formu gibi) sistem içerisinde yer almaktadır. İlgili formların bir örneği Şekil 4'teki gibidir.

Platformda, geliştirilen depresif duygu durumu, kaygı ve strese ilişkin üç müdahale modülüne ek olarak bir gevşeme egzersizi de modülde yer almaktadır. Bu modül sayfasından da kullanıcılar isterler ise gevşeme egzersizi yapabilmektedirler. Gevşeme egzersizi sayfası Şekil 5'deki gibidir.

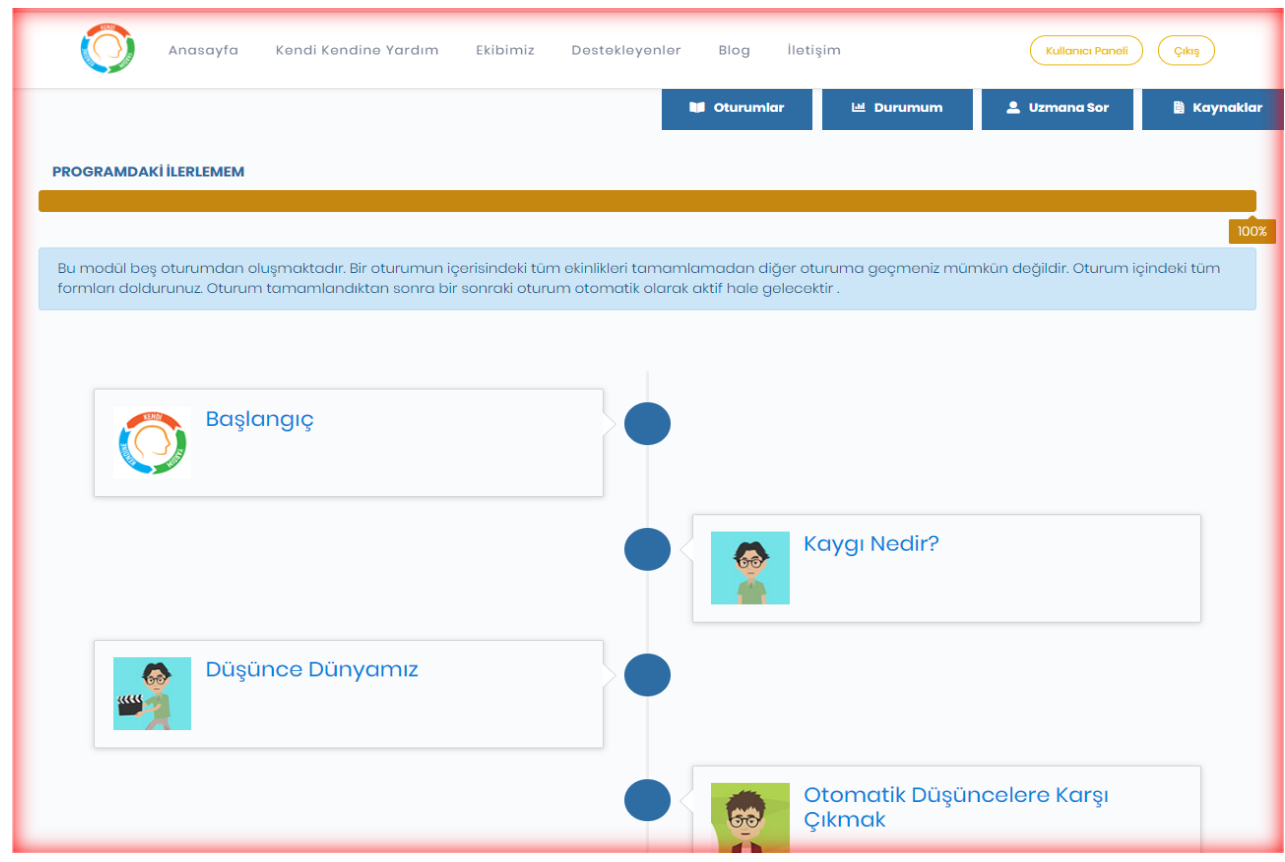

Şekil 3. Örnek Modül Ekranı (Kaygı Modülü)

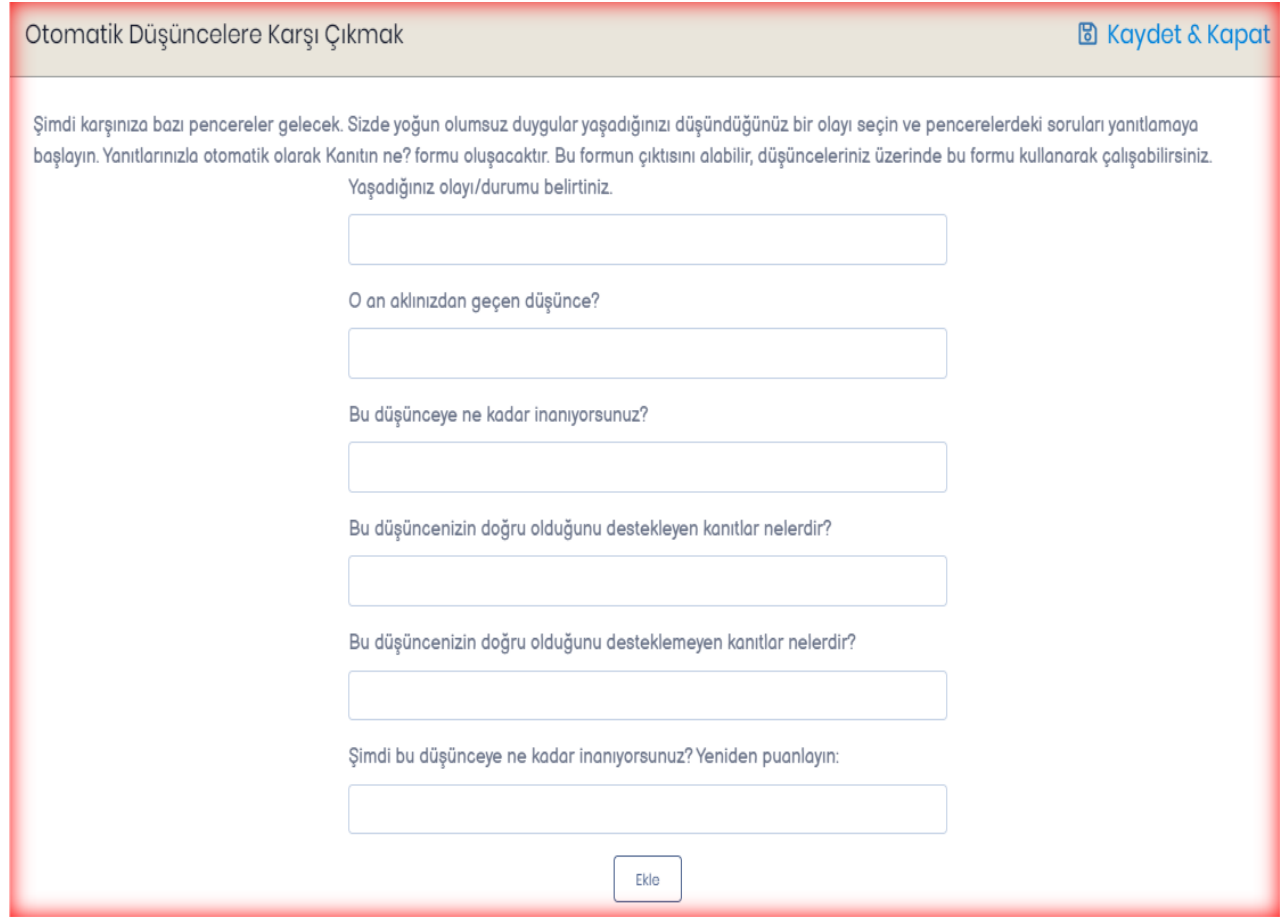

Şekil 4. Düşünce Kayıt Formu 


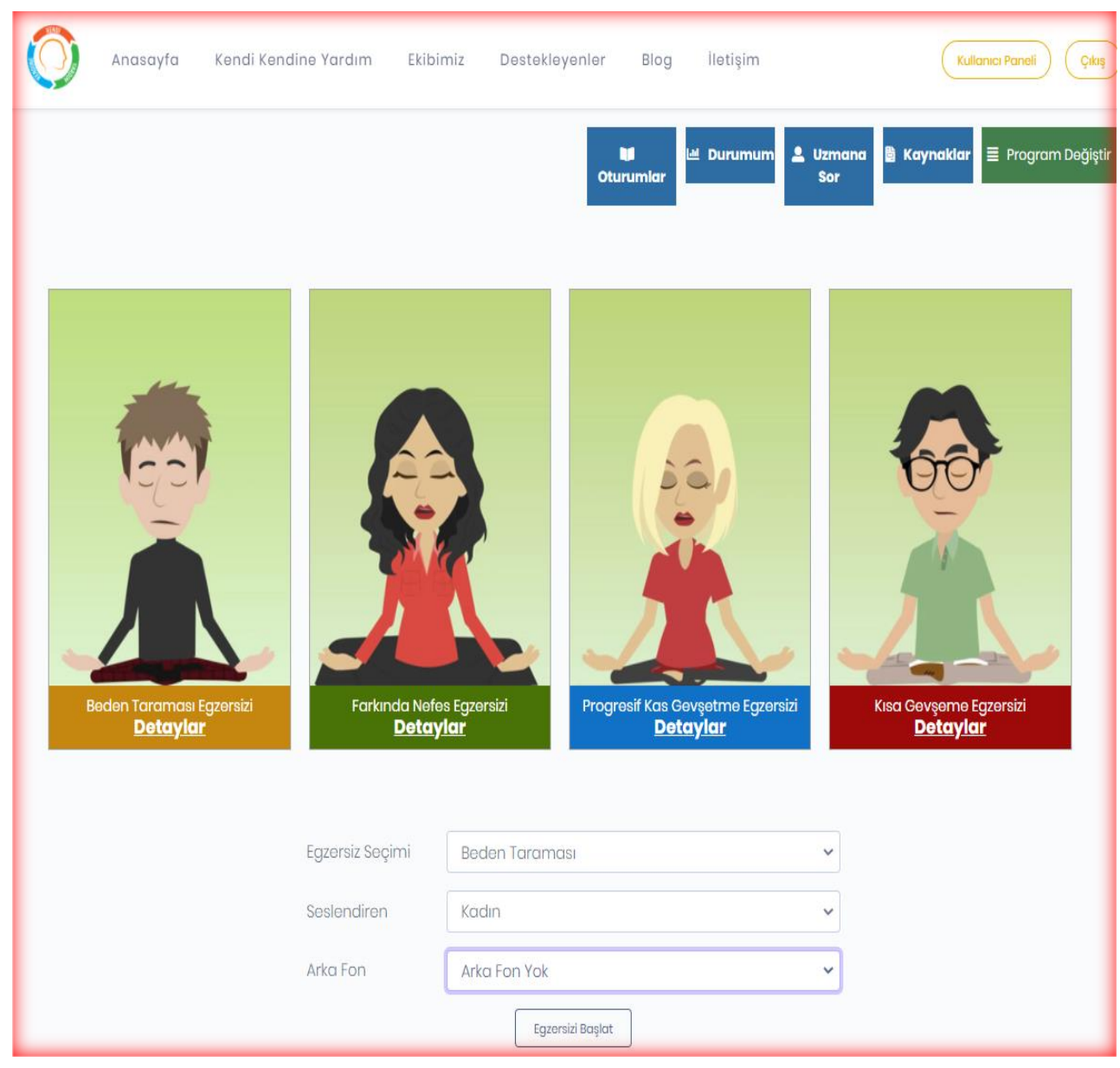

Şekil 5. Gevşeme egzersizleri ekranı

Şekil 5'te görüleceği üzere gevşeme egzersizi modülünde kullanıcılar meditasyon, deniz ve kuş seslerinden birini seçerek arka plan sesi olarak bunları kullanabilmektedirler. Böylece kendilerine en uygun ve odaklanmalarını kolaylaştıracak gevşeme egzersizi kombinasyonunu yaratabilmektedirler. Gevşeme egzersizi modülü diğer müdahale modüllerden bağımsız olarak kullanılabilmeleri sözkonusudur.

\subsection{Değerlendirme}

Uzaktan destek sistemlerinin değerlendirilmesi amacı ile kullanılan ölçütlerden biri de web sayfasının ya da sistemin değerlendirilmesidir. Bu kapsamda KKY platformunun değerlendirme aşaması için alan uzmanlarından sistemi kullanabilirlik açısından değerlendirmeleri istenmiştir. Kullanılabilirlik alanyazında bir çok farklı boyutu içeren kapsamlı bir değerlendirme olarak dikkate alınmaktadır. Araştırmacılar kullanılabilirliği farklı tanımlamış olsalar da, bir sistemin kullanılabilirliğinin boyutları etkinlik, fayda, geçerlilik, hata toleransı, kolay hatırlanabilirlik, kullanım kolaylığı, memnuniyet, öğrenilebilirlik ve verimli kullanım olarak ifade edilmektedir (Kılıç Çakmak, Güneș, Çiftçi ve Üstündağ, 2011). Kullanılabilirliği değerlendirmek amacı ile Web Sitesi Kullanılabilirlik Ölçeği'nin alt boyutları (Kılıç Çakmak vd., 2011) dikkate alınmıştır. Bu ölçeğin alt boyutları gezinme kolaylığı, tasarım, ulaşım kolaylığı ve erişim kolaylığı alt boyutlarından oluşmaktadır. Ölçme aracının alt boyutları dikkate alınarak hazırlanan anket formunda her bir alt boyutun kısaca tanımlaması yapılmış ve değerlendiricilerden bu boyutlar açısından KKY platformunu beşli derecelendirme (1: Hiç Uygun Değil - 5 : Tamamen Uygun) ölçeği üzerinde belirtmeleri istenmiştir. Ayrıca, ölçme aracının alt boyutlarına ek olarak sistem içindeki materyallerin bilişsel davranışçı terapi yaklaşımına uygunluğu da değerlendiricilere sorulmuştur. 
Her bir alt boyut için on beş değerlendiriciden elde edilen yanıtların dağılımı Tablo 2 'de verilmiştir.

Tablo 2. Uzmanların KKY için Kullanılabilirlik ve BDT'ye Uygunluk Değerlendirmesi

\begin{tabular}{|c|c|c|c|c|c|}
\hline Değerlendirme Alanı / Puan & $\begin{array}{c}\text { Hiç } \\
\text { Uygun } \\
\text { Değil (1) }\end{array}$ & (2) & (3) & (4) & $\begin{array}{l}\text { Tamamen } \\
\text { Uygun } \\
\text { (5) }\end{array}$ \\
\hline Gezinme Kolaylığı & - & - & - & 7 & 8 \\
\hline Tasarım & - & - & 3 & 6 & 6 \\
\hline Ulaşım Kolaylığı & - & - & & 5 & 10 \\
\hline Erişim Kolaylığı & - & - & & 6 & 9 \\
\hline Genel Kullanılabilirlik & - & - & & 4 & 11 \\
\hline BDT'ye Uygunluk & - & - & & 4 & 11 \\
\hline
\end{tabular}

Tablo 2 'de görüldüğü üzere tüm alanlarda uzmanlar ağırlıklı olarak 4-5 puan (uygun, tamamen uygun) vermişlerdir. Tasarım alt boyutunda üç katılımcı 3 olarak puanlama yapmış ve bu alt boyut en düșük puana sahip olan alt boyut olarak gözlenmiștir. Uzmanlar en yüksek puanı genel kullanılabilirlik ve BDT yaklaşımına uygunluk bağlamında vermiştir. Tüm ortalamalar birlikte değerlendirildiğinde platformun kullanılabilirlik düzeyinin yüksek olduğu ifade edilebilir.

\section{SONUÇ VE ÖNERILER}

$\mathrm{Bu}$ çalıșmada, Türkiye'de pandemi sürecinde giderek artan bireylerin psikolojik yardım ihtiyaçlarının karşılanmasına ve geniş bir kesimin psikolojik yardıma erişebilirliğine katkı sağlamak ve pandemi sürecinde bireylerin yoğun biçimde yaşamaları olası psikolojik belirtileri azaltmalarına yardım etmek üzere çevrimiçi temelli kendi kendine psikolojik yardım (KKY) destek platformu geliştirmek amaçlanmıştır. ADDIE modeline dayalı olarak platform geliştirilmiş olup, platform depresif duygudurum, kaygı ve stres olmak üzere üç müdahale modülü ve her bir modülde ise beşer oturum içeriği yer almaktadır. Ayrıca, bu üç müdahale modülünün yanı sıra bir gevşeme egzersizi modülüne de yer verilmiştir. Geliștirilen modül halen http://kendikendineyardim.org adresinden tüm kullanıcılar için Türkçe olarak kullanıma açıktır. Platformun kullanımını yaygınlaştırmaya ve tanıtımına yönelik duyurular, çevrim içi yollar ile yapılmaya devam etmektedir.

Günümüzde psikolojik yardım hizmetleri açısından kendi kendine yardım sistemleri özellikle toplum ruh sağlığı alanında giderek yaygınlaşan uygulamalar haline gelmiştir. Bu uygulamalar sayesinde daha geniş kitlelere, daha uygun maliyetlerle hizmet sunulması mümkün olmaktadır. Mevcur çalışmanın bu alanda gerçekleştirilen ilk uygulama olmasının Türkiye'deki araştırmacıların konuya olan ilgilerini artıracağı ve farklı problem alanlarına yönelik müdahale programları geliştirilmesi için bir başlangıç noktası olacağı düşünülmektedir. Bu yönü ile mevcut geliştirilen platformun bir ön çalışma niteliğinde olduğu ve mevcut sınırlılıkları içerisinde değerlendirilmesi gerektiği göz önünde bulundurulmalıdır.

KKY platformu halen kullanıcılar tarafından aktif olarak kullanılmakla birlikte, platformbazı sınırlılıklara da sahiptir. Bu çerçevede, KKY platformu pandemi süreci koşulları içerisinde bireylerin artan psikolojik yardım ihtiyaçlarına katkı sağlamak üzere çok kısa zamanda bir ekip çalışmasının sonucu ortaya çıkmıştır. Bu nedenle, KKY platformunun içeriği pandemi sürecinde en yoğun yaşanması olası psikolojik yardım alanlarından depresif duygudurum, kaygı ve stres konuları ile sınırlı kalmıştır. İlerleyen süreçte platformun içeriğin değerlendirilmesine ihtiyaç vardır. $\mathrm{Bu}$ kapsamda platformun araştırma-geliştirme çalışmaları için kullanıcılar ile 
değerlendirmeye yönelik etkililik ve izleme araştırmaları gerçekleştirilebilir. Platformun içeriğinin daha fazla içerik sağlayacak biçimde zenginleştirilebilir ve genişletilebilir. Ayrıca, ileride platforma sosyal kaygı, madde bağımlılığı, obsesif kompulsif bozukluk gibi problem alanlarına yönelik kendi kendine yardım içerikleri de üretilerek eklenebilir. Sadece problem alanlarına yönelik uygulamalar değil psikolojik sağlamlık, özsaygı gibi pozitif psikoloji alanında sıklıkla çalışılan kavramlara ilişkin kazanımlar da kendi kendine yardım sistemleri ile bireylere kazandırılabilir. Bu platform, özellikle herhangi bir psikiyatrik tanısı olmayan yetişkin bireylere kendi kendine psikolojik yardım kapsamında geliştirilmiştir. Dolayısıyla KKY platformu bir kendi kendine yardım uygulaması sınırlı̆̆ çerçevesinde değerlendirilmelidir. Platformun gerçek ortamda yüz yüze gerçekleștirilen ve profesyonel bir uzman tarafından sağlanan bir psikolojik yardımın alternatifi olarak değerlendirilmemelidir. Bu durum ve sınırlılık, platform içeriğinde sıklıkla vurgulanmakta olup, kullanıcılar gerektiğinde profesyonel bir yardım almaları için yönlendirilmektedir. Ayrıca, platform psikiyatrik tanısı olan klinik gruplarda kendi kendine yardım uygulamaları kapsamında geliştirilecek uygulamalar için bir model olarak kullanılabilir. Yine, çocuk ve ergen gruplarına özgü kendi kendine yardım içerikleri de hazırlanarak platformun daha küçük yaş gruplarında da kullanımı sağlanabilir ve kullanıcı yaş aralığı genişletilebilir. Mevcut platform bu aşamada çoklu ortam materyalleri içeren bir çevrimiçi uygulama içeriğine sahiptir. Bu platform içeriği ilerleyen çalışmalarda kendi içinde yapay zeka ve karar destek sistemleri içeren müdahale programları ile desteklenerek daha da genişletilebilir.

\section{Teșekkür}

KKY platformunun gelistirilmesinde proje Ekibinde yer alan Prof. Dr. Esra CEYHAN, Dr. Ferhat BAYOĞLU, danışman olarak yer alan Prof. Dr. Kadir ÖZDEL'e, içerik geliştirici olarak yer alan Dr. Öğretim Üyesi Zeynep SET, Uzman Psikolojik Danışman Ahmet ALTINOK, Doç. Dr. Mustafa Kemal YÖNTEM, Öğretim Görevlisi Burak KÖKSAL, Öğretim Görevlisi Nilay ÖZER ve Doç. Dr. Uğur Doğan'a katkılarından ötürü teşekkür ederiz.

\section{KAYNAKLAR}

Andersson, G., Bergstrom, J., Buhrman, M., Carlbring, P., Hollandare, F., Kaldo, V., ... Waara, J. (2008). Development of a new approach to guided self-help via the internet: The Swedish experience. Journal of Technology in Human Services, 26(2-4), 161-181. https://doi.org/10.1080/15228830802094627

Barak, A., Hen, L., Boniel-Nissim, M., \& Shapira, N. (2008). A Comprehensive Review and a Meta-Analysis of the Effectiveness of Internet-Based Psychotherapeutic Interventions. Journal of Technology in Human Services, 26(2-4), 109-160. https://doi.org/10.1080/15228830802094429

Barak, A., Klein, B., \& Proudfoot, J. G. (2009). Defining internet-supported therapeutic interventions. Annals of Behavioral Medicine, 38(1), 4-17. https://doi.org/10.1007/s12160-009-9130-7

Baumgartner, C., Bilevicius, E., Khazaal, Y., Achab, S., Schaaf, S., Wenger, A., ... Schaub, M. P. (2019). Efficacy of a web-based self-help tool to reduce problem gambling in Switzerland: Study protocol of a two-Armed randomised controlled trial. BMJ Open, 9(12), e032110. https://doi.org/10.1136/bmjopen-2019-032110

Boettcher, J., Magnusson, K., Marklund, A., Berglund, E., Blomdahl, R., Braun, U., ... Carlbring, P. (2018). Adding a smartphone app to internet-based self-help for social anxiety: A randomized controlled trial. Computers in Human Behavior, 87, 98-108. https://doi.org/10.1016/j.chb.2018.04.052

Brooks, S. K., Webster, R. K., Smith, L. E., Woodland, L., Wessely, S., Greenberg, N., \& Rubin, G. J. (2020, Mart 14). The psychological impact of quarantine and how to reduce it: rapid review of the evidence. The Lancet, C. 395, ss. 912-920. https://doi.org/10.1016/S0140-6736(20)30460-8

Buntrock, C., Ebert, D. D., Lehr, D., Smit, F., Riper, H., Berking, M., \& Cuijpers, P. (2016). Effect of a web-based guided self-help intervention for prevention of major depression in adults with subthreshold depression a randomized clinical trial. JAMA - Journal of the American Medical Association, 315(17), 1854-1863. 
https://doi.org/10.1001/jama.2016.4326

Buscher, R., Torok, M., \& Sander, L. (2019). The effectiveness of internet-based self-help interventions to reduce suicidal ideation: Protocol for a systematic review and meta-analysis. JMIR Research Protocols, 8(7), e14174. https://doi.org/10.2196/14174

Cava, M. A., Fay, K. E., Beanlands, H. J., McCay, E. A., \& Wignall, R. (2005). The experience of quarantine for individuals affected by SARS in Toronto. Public Health Nursing, 22(5), 398-406. https://doi.org/10.1111/j.0737-1209.2005.220504.x

Clark, D. A., \& Steer, R. A. (1996). Empirical status of the cognitive model of anxiety and depression. In P. M. Salkovskis (Ed.), Frontiers of cognitive therapy (p. 75-96). The Guilford Press.

Cowpertwait, L., Clarke, D., Cowpertwait, L., \& Clarke, D. (2013). Effectiveness of Web-based Psychological Interventions for Depression: A Meta-analysis. Int J Ment Health Addiction, 11, 247-268. https://doi.org/10.1007/s11469-012-9416-z

De Jaegere, E., van Landschoot, R., van Heeringen, K., van Spijker, B. A. J., Kerkhof, A. J. F. M., Mokkenstorm, J. K., \& Portzky, G. (2019). The online treatment of suicidal ideation: A randomised controlled trial of an unguided web-based intervention. Behaviour Research and Therapy, 119, 103406. https://doi.org/10.1016/j.brat.2019.05.003

Durdu Akgün, B., Aktaç, A., \& Yorulmaz, O. (2019). Ruh Sağlığında Mobil Uygulamalar: Etkinliğe Yönelik Sistematik Bir Gözden Geçirme. Psikiyatride Guncel Yaklasimlar - Current Approaches in Psychiatry, 11(4), 519-530. https://doi.org/10.18863/pgy.441765

Erdem, A., \& Özdemir, M. (2020). Çevrimiçi ve Yüz Yüze Psikolojik Danışmaya İlişkin Algıları Keşfetmek: Nitel Bir Çalışma. Psikiyatride Guncel Yaklasimlar - Current Approaches in Psychiatry, 12(Suppl 1), 331363. https://doi.org/10.18863/pgy.793232

Gaebel, W., \& Stricker, J. (2020). E-mental health options in the COVID-19 pandemic and beyond. Psychiatry and Clinical Neurosciences, 74(8), 441-442. https://doi.org/10.1111/pcn.13079

Hamilton, K. E., \& Dobson, K. S. (2002). Cognitive therapy of depression: Pretreatment patient predictors of outcome. Clinical Psychology Review, 22(6), 875-893. https://doi.org/10.1016/S0272-7358(02)00106-X

Hartmann-Boyce, J., Jebb, S. A., Fletcher, B. R., \& Aveyard, P. (2015, Mart 1). Self-help for weight loss in overweight and obese adults: Systematic review and meta-analysis. American Journal of Public Health, C. 105, ss. e43-e57. https://doi.org/10.2105/AJPH.2014.302389

Hisli Şahin, N., \& Durak, A. (1994). Kısa Semprom Envanteri (Brief Symptom Inventory-BSI): Türk gençleri için uyarlanması. Türk Psikloji Dergisi, 9(31), 44-56.

Hisli Şahin, N., Durak Batıgün, A., \& Uğurtaş, S. (2002). Kısa Semptom Envanteri (KSE): Ergenler İçin Kullanımının Geçerlik, Güvenilirlik ve Faktör Yapısı. Türk Psikiyatri Dergisi, 13(2), 125-135.

Hofmann, S. G. (2007). Cognitive factors that maintain social anxiety disorder: A comprehensive model and its treatment implications. Cognitive Behaviour Therapy, 36(4), 193-209. https://doi.org/10.1080/16506070701421313

Johansson, M., Sinadinovic, K., Hammarberg, A., Sundström, C., Hermansson, U., Andreasson, S., \& Berman, A. H. (2017). Web-Based Self-Help for Problematic Alcohol Use: a Large Naturalistic Study. International Journal of Behavioral Medicine, 24(5), 749-759. https://doi.org/10.1007/s12529-016-9618-z

Kazlauskas, E., Eimontas, J., Olff, M., Zelviene, P., \& Andersson, G. (2020). Adherence Predictors in InternetDelivered Self-Help Intervention for Life Stressors-Related Adjustment Disorder. Frontiers in Psychiatry, 11(March), 1-7. https://doi.org/10.3389/fpsyt.2020.00137

Khanna, M., Aschenbrand, S. G., \& Kendall, P. C. (2007). New frontiers: Computer technology in the treatment 
of anxious youth. Behav Ther, 30, 22-25.

Kılıç Çakmak, E., Güneş, E., Çiftçi, S., \& Üstündağ, M. T. (2011). Web Sitesi Kullanılabilirlik Ölçeğinin Geliştirilmesi : Geçerlik , Güvenirlik Analizi ve Uygulama Sonuçları. Pegem Eğitim ve Öğretim Dergisi, 1(2), 31-40.

Koçyiğit, M., \& Erkan, Z. (2021). Covid- 19 Sürecinde Psikolojik Danışma ve Süpervizyon: \# evdekal Deneyimi Counseling and Supervision During Covid-19 : Experience of \# stayhome. 8(1), 253-274.

Lambert, J. D., Greaves, C. J., Farrand, P., Price, L., Haase, A. M., \& Taylor, A. H. (2018). Web-based intervention using behavioral activation and physical activity for adults with depression (the emotion study): Pilot randomized controlled trial. Journal of Medical Internet Research, 20(7), 1-15. https://doi.org/10.2196/10112

Lee, E. B., Hoepfl, C., Werner, C., \& McIngvale, E. (2019). A review of tech-based self-help treatment programs for Obsessive-Compulsive Disorder. Journal of Obsessive-Compulsive and Related Disorders, 23(June). https://doi.org/10.1016/j.jocrd.2019.100473

Meredith, L. N., \& Frazier, P. A. (2019). Randomized Trial of Web-Based Stress Management Interventions for Community College Students. Community College Journal of Research and Practice, 43(1), 42-53. https://doi.org/10.1080/10668926.2017.1396267

Özdemir, M. B., \& Barut, Y. (2020). Psikolojik Danışma Uygulamalarında Post Modern Bakış Açısı: Çevrimiçi Psikolojik Danışma. Cyprus Turkish Journal of Psychiatry \& Psychology, 2(3), 192-199. https://doi.org/10.35365/ctjpp.20.03.24

Özer, Ö., Ylkılmaz, M., Altınok, A., \& Bayoğlu, F. (2016). Psikolojik Danışmanların Çevrimiçi (Online) Psikolojik Danışmaya Yönelik Tutumlarının Danışan Perspektifinden İncelenmesi. Akademik Bakış Dergisi, 58(Kasım-Aralık), 549-559. Tarihinde adresinden erişildi http://www.akademikbakis.org

Özerbaş, M. A., \& Kaya, A. B. (2017). Öğretim Tasarımı Çalışmalarının İçerik Analizi: ADDIE Modeli Örneklemi. Türk Eğitim Bilimleri Dergisi, 15(1), 26-42.

Pan, P. J. D., Chang, S. H., \& Yu, Y. Y. (2005). A support group for home-quarantined college students exposed to SARS: Learning from practice. Journal for Specialists in Group Work, 30(4), 363-374. https://doi.org/10.1080/01933920500186951

Radtke, T., Ostergaard, M., Cooke, R., \& Scholz, U. (2017). Web-based alcohol intervention: Study of systematic attrition of heavy drinkers. Journal of Medical Internet Research, 19(6), e6780. https://doi.org/10.2196/jmir.6780

Riper, H., Spek, V., Boon, B., Conijn, B., Kramer, J., Martin-Abello, K., \& Smit, F. (2011). Effectiveness of E-Selfhelp interventions for curbing adult problem drinking: A meta-analysis. Journal of Medical Internet Research, 13(2), e1691. https://doi.org/10.2196/jmir.1691

Riva, G., Bernardelli, L., Browning, M. H. E. M., Castelnuovo, G., Cavedoni, S., Chirico, A., ... Wiederhold, B. K. (2020). COVID Feel Good-An Easy Self-Help Virtual Reality Protocol to Overcome the Psychological Burden of Coronavirus. Frontiers in Psychiatry, 11(September), 1-9. https://doi.org/10.3389/fpsyt.2020.563319

Roepke, A. M., Jaffee, S. R., Riffle, O. M., McGonigal, J., Broome, R., \& Maxwell, B. (2015). Randomized Controlled Trial of SuperBetter, a Smartphone-Based/Internet-Based Self-Help Tool to Reduce Depressive Symptoms. Games for Health Journal, 4(3), 235-246. https://doi.org/10.1089/g4h.2014.0046

Rosen, G. M. (1987). Self-Help Treatment Books and the Commercialization of Psychotherapy. American Psychologist, 42(1), 46-51. https://doi.org/10.1037/0003-066X.42.1.46

Schaub, M. P., Tiburcio, M., Martinez, N., Ambekar, A., Balhara, Y. P. S., Wenger, A., ... Souza-Formigoni, M. L. O. (2018). Alcohol e-Help: study protocol for a web-based self-help program to reduce alcohol use in adults with drinking patterns considered harmful, hazardous or suggestive of dependence in middle-income 
countries. Addiction, 113(2), 346-352. https://doi.org/10.1111/add.14034

Schaub, M., Sullivan, R., Haug, S., \& Stark, L. (2012). Web-based cognitive behavioral self-help intervention to reduce cocaine consumption in problematic cocaine users: Randomized controlled trial. Journal of Medical Internet Research, 14(6). https://doi.org/10.2196/jmir.2244

Sevilla-Llewellyn-Jones, J., Santesteban-Echarri, O., Pryor, I., McGorry, P., \& Alvarez-Jimenez, M. (2018, Eylül 1). Web-based mindfulness interventions for mental health treatment: Systematic review and metaanalysis. Journal of Medical Internet Research, C. 20, s. e10278. https://doi.org/10.2196/10278

Stolz, T., Schulz, A., Krieger, T., Vincent, A., Urech, A., Moser, C., ... Berger, T. (2018). A mobile App for social anxiety disorder: A three-arm randomized controlled trial comparing mobile and PC-based guided self-help interventions. Journal of Consulting and Clinical Psychology, 86(6), 493-504. https://doi.org/10.1037/ccp0000301

Tian, F., Li, H., Tian, S., Yang, J., Shao, J., \& Tian, C. (2020). Psychological symptoms of ordinary Chinese citizens based on SCL-90 during the level I emergency response to COVID-19. Psychiatry Research, 288. https://doi.org/10.1016/j.psychres.2020.112992

Torok, M., Han, J., Baker, S., Werner-Seidler, A., Wong, I., Larsen, M. E., \& Christensen, H. (2020). Suicide prevention using self-guided digital interventions: a systematic review and meta-analysis of randomised controlled trials. The Lancet Digital Health, 2(1), e25-e36. https://doi.org/10.1016/S25897500(19)30199-2

Türk Psikiyatri Derneği (2020). Karantinanın Ruhsal Etkileri ve Koruyucu Önlemler . https://psikiyatri.org.tr/TPDData/uploads/files/KarantinaCOVID.pdf adresinden edinilmiștir.

Urech, C., Grossert, A., Alder, J., Scherer, S., Handschin, B., Kasenda, B., ... Hess, V. (2018). Web-based stress management for newly diagnosed patients with cancer (STREAM): A randomized, wait-list controlled intervention study. Journal of Clinical Oncology, 36(8), 780-788. https://doi.org/10.1200/JC0.2017.74.8491

van Spijker, B. A. J., Calear, A. L., Batterham, P. J., Mackinnon, A. J., Gosling, J. A., Kerkhof, A. J. F. M., ... Christensen, H. (2015). Reducing suicidal thoughts in the Australian general population through web-based self-help: Study protocol for a randomized controlled trial. Trials, 16(1), 1-10. https://doi.org/10.1186/s13063-015-0589-1

Van Straten, A., Cuijpers, P., \& Smits, N. (2008). Effectiveness of a web-based self-help intervention for symptoms of depression, anxiety, and stress: Randomized controlled trial. Journal of Medical Internet Research, 10(1), 1-11. https://doi.org/10.2196/jmir.954

Wang, C., Pan, R., Wan, X., Tan, Y., Xu, L., Ho, C. S., \& Ho, R. C. (2020). Immediate Psychological Responses and Associated Factors during the Initial Stage of the 2019 Coronavirus Disease (COVID-19) Epidemic among the General Population in China. International Journal of Environmental Research and Public Health, 17(5), 1729. https://doi.org/10.3390/ijerph17051729

, D. J., Portillo, C. J., Holzemer, W. L., Slaughter, R., \& McGhee, E. M. (2004, Kasım 10). The effectiveness of web-based vs. non-web-based interventions: A meta-analysis of behavioral change outcomes. Journal of Medical Internet Research, C. 6, s. e116. https://doi.org/10.2196/jmir.6.4.e40

Wittekind, C. E., Bierbrodt, J., Lüdecke, D., Feist, A., Hand, I., \& Moritz, S. (2019). Cognitive bias modification in problem and pathological gambling using a web-based approach-avoidance task: A pilot trial. Psychiatry Research, 272,171-181. https://doi.org/10.1016/j.psychres.2018.12.075

Yang, L., Yin, J., Wang, D., Rahman, A., \& Li, X. (2020). Urgent need to develop evidence-based self-help interventions for mental health of healthcare workers in COVID-19 pandemic. Psychological Medicine, 7(2020), 2020-2021. https://doi.org/10.1017/S0033291720001385

Yuen, E. K., Gros, K., Welsh, K. E., McCauley, J., Resnick, H. S., Danielson, C. K., ... Ruggiero, K. J. (2016). 
Development and preliminary testing of a web-based, self-help application for disaster-affected families. Health Informatics Journal, 22(3), 659-675. https://doi.org/10.1177/1460458215579292

Zeren, Ş. G. (2014). Information and Communication Technology in Education of Psychological Counselors in Training. International Online Journal of Educational Sciences, 6(2), 494-509.

Zeren, Ş. G., \& Bulut, E. (2018). Çevrimiçi Psikolojik Danışmada Etik ve Standartlar: Bir Model Önerisi. Türk Psikolojik Danışma ve Rehberlik Dergisi, 8(49), 63-80.

Zwerenz, R., Becker, J., Johansson, R., Frederick, R. J., Andersson, G., \& Beutel, M. E. (2017). Transdiagnostic, Psychodynamic Web-Based Self-Help Intervention Following Inpatient Psychotherapy: Results of a Feasibility Study and Randomized Controlled Trial. JMIR Mental Health, 4(4), e41. https://doi.org/10.2196/mental.7889 